\author{
Siergiej Grinev-Griniewicz \\ University of Bialystok
}

\title{
Terminological aspects of modern language policy
}

\begin{abstract}
Terminological aspects of language policy are discussed with a suggestion of introducing a new scientific discipline - linguopolitology with the respective conceptual and terminological systems; arguments for founding language planning on terminological basis and examples of regulating terminology are presented.
\end{abstract}

Keywords: language policy, language planning, advancing terminology, terminology design.

There is already a substantial amount of research on language policy, but relatively few publications touch upon terminological aspects of the subject, aside from mentioning that in the area of respective terminology there are many ambiguities, complicated by the fact that the field has a different terminological structure in different languages (Cillia and Busch 2006). In this article we are going to address the following tasks:

(1) presenting the basic conceptual system of this field of knowledge as viewed in the East Europe and suggesting the respective terminological system;

(2) briefly introducing modern language situation in Russia;

(3) considering terminological aspects of language policy and terminological experience in Russia, both negative and positive.

Exploration of political aspects of language and language policy has a considerable history. The beginning of scientific reflection on language policies and politics as an independent field was undertaken particularly in the 1960s and the focus was initially on the aspect of language planning. However, in the East Europe, particularly in the former USSR, already beginning in the 1920-s in connection with the large-scale elaboration of national languages there was a number of publications on the subject of language policy. Language planning activities were based on belief that in the socialist society all languages are equal and may be successfully controlled. Later on these ideas were incorporated in the Russian model of sociolinguistics though nowadays language policy as a field of study has outgrown the framework of sociolinguistics.

It should be mentioned that at the present time there is no consensus even on the name of the new science. According to B. Spolsky and R.D. Lambert just as with many new fields, there continues to be disagreement over the name of this one, variously called language policy, language treatment, language cultivation, language engineering, language planning, and language management (Spolsky and Lambert 2006). From the point of view of terminology science this is a normal situation - at the initial stage there usually are various names of a new science, reflecting different approaches and possible aspects to be taken into consideration. Nevertheless it is already possible to establish the general structure of a new science, its main divisions and direction of research on the basis of proposed definitions and the material under investigation. As for naming theoretical foundations of language policy we would like to suggest the term linguopolitology taking into consideration the existence of 
politology as the established science and on the analogy with the already existing science linguoculturology.

There is much in common in approaches to understanding language policy in the West and the East Europe. Whether language policy is defined as the commonly agreed set of choices of language varieties and the ideologies associated with those choices in a speech community, realised in language practices or in formal policy decisions such as laws, constitutions, or regulations (Spolsky and Lambert 2006) or the conception and planning of political activity with respect to language (Cillia and Busch 2006), or sum total of ideological principles and practical activities in solving language problems in community or state as part of national policy (Desheriev 1990), we may see as its main parts language ideology and language politics.

Language ideology is claimed to have emerged as a separate field of linguisticanthropological study in the last decades of the 20th century, combining linguistic ethnography with insights from the social-scientific study of ideology (Blommaert 2006). In our opinion, when we speak of language ideology we usually mean language strategy based on the existing language situation and on the assessment of the particular language or languages state - language estimation.

In language situation the following aspects may be distinguished:

- $\quad$ number of existing idioms (understanding idiom as the speech proper to a people or place; a dialect or local language);

- $\quad$ character of components of language situation (languages, dialects or subdialects);

- $\quad$ genetic relations of idioms (related, unrelated);

- $\quad$ functions of particular idioms;

- $\quad$ character of dominating idiom - native or imported (cf. Vinogradov 1990).

There are various types of language situation. It may be monolingual, bilingual or multilingual; exoglossal, being the sum total of different languages or endoglossal - the sum total of territorial and social dialects of the same language; balanced, if its components (languages or dialects) are functionally equipollent, or unbalanced, when its components are distributed by various spheres of communication and social groups (Shvejtser 1990).

In language estimation (language assessment) according to V.A. Vinogradov the quantitative characteristics are usually taken into consideration, such as demographic power (the number of native speakers in proportion to the whole number of inhabitants of the territory); communicative possibilities (the number of functions of particular idioms as related to total number of such functions); political status; prestigiousness; level of development; rate of change (development); lingual tendencies (cf. Vinogradov 1990).

The above mentioned factors should be taken into consideration in language strategy overt or implicit intensions concerning a language (or languages) - taking shape in respective approaches and realised in politics. Such strategy may be retrospective - directed at preservation of the existing state of a language (maintaining language culture, limiting overflows of borrowings, etc.) or perspective - aiming at language development, and also take form of lingual nationalism when minority languages are threatened and marginalized by the dominance of established national languages or lingual pluralism (language situation in Switzerland or Belgium where national languages have equal rights). 
Language politics may be defined as actual political activity with respect to language and can be distinguished from language policy, i.e., the conception and planning of such activity (Ammon 2006) or as practical activities in connection with language in community or state as part of national policy (Desheriev 1990). Objectives of language politics can vary greatly depending on interests and motives - e.g., 'purifying' one's own national language of foreign loans to shape it into a more adequate symbol of national identity, or spreading the language within the state or beyond. Language politics has to reckon with existing language rights and may result in new language rights (Paulston, 1997).

According to Ammon (2005), internal language politics regulates language within the polity, while external language politics aims beyond it. For the state, the former is part of interior politics, the latter of exterior politics. Internal language politics can be directed at language structure (language corpus politics) or language status and function (language status politics). Typical aims of corpus politics are introducing or regulating script and orthography; standardization, including selection and codification of norms of spelling, pronunciation, vocabulary, grammar, and style or texts; purification - eliminating foreign loans; and modernization (developing modern terminology). Typical aims of status politics are spreading the norm of a standard variety and, in the case of multilingual communities, allocating languages to certain regions or domains and functions - for example, official, educational (medium or subject of teaching on various educational levels; religious, the media, or the military. Politics of language promotion, language maintenance, or language revival can comprise corpus politics, such as constructing or reconstructing vocabulary, as well as status politics, such as encouraging use in the family or institutionalization in school (Ammon 2005).

Judging by the accumulation of names (apart from language politics) for this concept in the last 40 years - such as language treatment, language cultivation, language engineering, language planning, and language management - it is a very important concept implying a wide spectre of activities. As in many similar cases those synonyms should be rather used, in accordance with their usual meanings, as names for particular aspects of language politics. In our opinion two general aspects of language politics should be distinguished first of all language approach and language management.

There are two types of language approach - either language cultivation or hindering of language development. In the case of language cultivation creating beneficial conditions for development of language may take various forms - simply promoting language by improving its state, raising its prestige, advancing its vocabulary, simplifying its orthography and grammar, introducing benefits for its usage (preferences in communication, availability of literature, widening the scope of its usage, etc.), launching campaigns of promotion, state measures, such as standardization of a chosen language.

In some cases, language cultivation may take form of language reviving. It may also take the form of language imposing, which contradicts the universally accepted notion of language rights but is still practiced in some European countries.

Hindering (hampering, oppressing) language also may take various forms beginning with language retarding by official and unofficial means, direct language blocking (obstructing its development) and language extermination.

Language management has three components: the development of explicit language plans and policies which we suggest to call language planning proper, their implementation (by rules or laws or resource allocation), which we suggest to call language regulation, and the evaluation of results and effects. 
When we speak about various actions constituting language management we should first consider terminological activities for a number of reasons. Firstly, language development primarily consists of vocabulary growth, the lexical level of the language system being more inclined to changes than other levels. As was already pointed out in a number of publications (cf. Griniewicz 2006, Grinev-Griniewicz 2008), the growth of scientific and technical vocabularies is much faster than that of the everyday speech vocabulary, so at present the number of terms in some sciences (for example chemistry or biology) greatly exceeds the number of common words. We can compare the following figures: the largest Russian 17volume dictionary treats some 120,000 words (though already there are bilingual Russian dictionaries containing about 200,000 words); at the same time Russian construction terminology numbers more than 150,000 words and in chemistry more than 1 million substances are known, each with its own name. According to Wikipedia modern biological terminology may now reach even up to 100 million names for varieties of living beings, and probably nowadays special lexical units comprise not $90 \%$, but rather more than 99 percent of new words in modern languages. This tendency would remain, because special vocabulary not only already constitutes the major part of any advanced national language but also is the most dynamic strata of language, for every 25 years the number of sciences and scientific disciplines grows twice, and every new science brings its own terminology. If we consider the fact that according to the Encyclopaedia Britannica in the $20^{\text {th }}$ century as much as 2,500 new sciences and scientific disciplines came into being, then the problem of terminology in the $21^{\text {st }}$ century takes it proper shape.

Secondly, lately there appeared definite political reasons to pay more attention to regulation of special vocabulary. Presently terminology science concerns itself with globalisation of the industry, economics, culture, even everyday life that results in forming new conditions of the existence and interaction of national languages. One of them is the lessening of the number of the actively used languages. According to some calculations during the current century approximately $90 \%$ of the presently functioning 6,000 languages will disappear from active usage. These statements sound tragically but the source of such statements may be rather terminological mistake when not only dialects, but sometimes even sub-dialects (one-village dialects) as well are erroneously viewed as languages (all sources maintain that it is difficult to give an exact figure of the number of languages that exist in the world, because the difference between a language and a dialect is not always clear).

For example, in Dagestan some of the languages, such as chamalinskij, bagvalinskij, botlihskij, godoberihskij, bezhtinskij, hvarshinskij, gunzibskij, ginuhskij, archinskij, buduhskij and hinalugskij - are used by less than 5 thousand people each and do not have written form. They are close to losing the status of independent languages. It does not mean that they would completely disappear - rather they would be rightly called dialects of the closest wider used languages (some of them are already called dialects in the latest linguistic publications). Disappearance of dialects is a quite natural process - due to centralisation tendencies at the period of forming new states in Europe in Modern Times local dialects stepped aside and the central dialect served as the basis for a national language. Narrowing of the sphere of application of a language transforming it into a local dialect is sometimes accelerated by the influence of a closely related language with the traditionally wide spectre of functioning (such is the case of the Ukrainian and the Byelorussian languages which at the end of the 1980-s were being almost completely ousted by the Russian language).

It follows that the surviving languages will widen their functional domain and sometimes even territory outside the countries of their origin (it might be mentioned as a curious fact that at the present time both the British and the Russians constitute national 
minorities among the native speakers of the respective languages). And here the question of the sound national language policy arises.

The emergence of the independent national states in the place of the former USSR was followed by lending official statuses to many national languages and this caused some difficulties. Some of these languages were not enough developed to fulfil the role of means of official and scientific communication. Often a large part of the inhabitants of the newly found states had no knowledge of the official language and would not like to learn it. At the same time, due to the pressure of the nationalist movements, laws considering language policy became more and more strict.

In the Russian Federation with the disbanding of the Soviet Union, there appeared a new set of republics, many being formed from the previous Autonomous Soviet Socialist Republics (e.g., the Chuvash Republic or the Republic of Tatarstan). Of the 21 Republics in the Russian Federation at the end of the 20th century, 15 had instituted language laws to grant their titular language equal official status with Russian. In addition, the Constitutions of these Republics include language-specific articles in most cases granting official status to the titular language and Russian, and sometimes other languages as well. At present, a number of languages have official status in the Russian Federation, Russian being the state language for the entire country (Grenoble 2006).

At the beginning of the 1990s, it seemed that every language would be used in all spheres of communication. The first Russian "Law of the languages of the peoples of the Russian Soviet Federated Socialist Republic" from 1991 envisaged creating translating offices in all central institutions to enable communication with minorities in all possible languages. It was found impossible and at the end of 1990s this item disappeared from the amended law. Russian is used as lingua franca and as for now cannot be substituted by any other means. For example, according to V.M. Alpatov, in Kalmyk Republic in 1993 it was planned to completely abolish Russian and turn to Kalmyk in the country and English in outside communication. It failed for a number of reasons. In the Soviet period lots of books, journals and newspapers were published in Kalmyk, while now most journals and newspapers disappeared, there are almost no books in Kalmyk and the only central newspaper remains bilingual, where official news are presented in Kalmyk and the rest in Russian. At the Soviet period publications in Kalmyk were financed by the state, now they became commercial. At the Soviet period literature in national languages was artificially supported, some foreign books translated into national languages, but not Russian - for example Somerset Maugham's "Cakes and Ale" for a long time was available in Ukrainian, but not in Russian. Some minority languages now function only in oral form. In Khakass when the primary school manuals were published in Khakass, it turned out that the absolute majority of Khakass children know only Russian and can not use them. In Komi-Permiak republic attempts to introduce native language into any official sphere failed completely. In languages of the peoples of North the majority of languages, having a small number of native speakers are now disappearing. It seems that with the advent of capitalism position of the Russian language became even stronger (Alpatov 2005).

At present we can see that some of the political decisions concerning language in the new states have only momentary political reasons with complete ignorance of the natural tendencies of language development and cannot therefore be taken seriously. Some of the new official languages still lack words to denote quite common ideas and are now hastily being enlarged. In the Tajik language words like student, university and institute which had international character and were extensively used were hastily replaced by clumsy national constructions which created and still create many inconveniences. I am acquainted with the author of the Tajik medical dictionary containing 300 thousand terms, whose colleague told 
me that the only person using those terms is the author, because medical students have to learn Latin, Russian and English terminology and have no time to learn terms not used in practice.

Therefore, working out sound impartial recommendations based on the analysis of natural processes of evolution and, in particular, international interaction of languages becomes a necessity. Such recommendations should be concerned with terminology for a number of reasons.

Firstly, in contrast to the common everyday vocabulary that is relatively stable and is not susceptible to administrative changes, the special vocabulary may be regulated. Terminology always is a result of agreement on usage of certain names of concepts in the respective field of knowledge. Therefore special vocabulary is quite probably the only part of language that might be consciously manipulated and controlled. In many languages it is possible to work out sets of rules for coining new special lexical units and regulating the existing ones. There are reasons to believe that the most numerous layer of special word-stock consisting of the so-called nomens may be successfully regulated and developed according to the pre-established sets of rules.

Secondly, it should be mentioned that some linguistic problems, especially of the semantic nature (such as polysemy or synonymy) could be much more clearly appraised in the domain of terminology due to the precise nature of terms.

Thirdly, controlling special vocabulary may enhance the progress of science and technology. The success of contemporary research of the laws of thinking (especially creative) and simulating thinking processes, investigating development of human civilisation and stimulating scientific and technological progress largely depend on solving a number of terminological problems.

Finally, the latest anthropolinguistic data give reason to believe in certain correspondences between the size of national vocabulary and the level of the national mentality. Therefore terminological aspects ought to be necessarily taken into consideration in language strategy decisions. Conscious language policy in the form of language management (especially in preserving and advancing minor languages) should concern itself first of all with advancing special vocabulary.

Language planning, especially long-term planning should be based on systemic overall analysis of the existing state of terminology and close examination of the present trends and tendencies some of which are already known (Grinev 1993), prognostication of language development and establishing directions and modes of regulating special vocabulary.

Practical terminological work as a crucial part of language policy should presuppose systemic approach based on sound knowledge of main characteristics of terminologies. Experience of terminological work in the former USSR showed this to be quite a difficult task. As was mentioned in (Grinev 1994) the peculiar character of the Soviet terminological activities and the respective theory was strongly influenced by the initial belief that language development could be managed and taken under the human control based on Marx' saying that language would be one of the things to be taken under control by the victorious proletariat. Later (up to the present time) the idea of the human control was substituted by the idea of the state control which was reflected in the obligatory character of terminological standardization in the USSR. It is difficult to find in the Soviet standards permitted synonyms or polysemic terms which we can view in the British, Indian, Australian or New Zealand terminological standards; and that is also why discussions of terminological standards in Russia sometimes take very fierce character. 
The first attempts to bring the language to the proper ordered state and to substitute the current terms by the ideal ones were unsuccessful. According to the evidence of the founder of the Russian terminology school D.S. Lotte, the cause of this failure was the complete ignorance of the character of the object of ordering (language) and the absence of the principles of terminology ordering. Therefore terminology science appeared as means of theoretical foundation of the practical work.

Unfortunately now in Russia and some other countries we evidence lack of conscious systematic terminological work based on elementary principles of planning and knowledge of language tendencies. Enormous amount of terminological standards prepared in the 1960s and 1970s were carried out unsystematically and without sound principles, some of them being of poor quality. Terminological standards of the Comecon countries were much better, but were based not on the overall systemic approach, but rather on choosing separate subject fields. Much closer to the optimal conditions was the All-Union endeavour to elaborate linguistic means of the branch information-retrieval systems to be united in an overall system that was undertaken at the end of the 1970s. Unfortunately this work was not correctly finished.

Nowadays when terminological efforts in Russia are determined by financial means and are not supported by the state the situation is much worse. There is no evidence of any attempts to organise planned wide-scale regulation of special lexis as yet. One of the reasons that governments pay no attention to opportunities for developing national special languages is that the cases of immediate losses from hampering of scientific progress could not be exactly measured. Therefore the development of special vocabulary, creating conditions for scientific, industrial and cultural development, which should be one of the priorities in planning and financing, in many countries is sadly neglected and only carried out by the efforts of a small number of enthusiasts. Some terminological activities are necessarily accompanying scientific research, but in the absence of special training and co-ordination, these activities are carried out in an unsystematic way, based only on commonsense, which is characteristic of primitive cultures and states of cognition.

At the same time some principles and successful attempts at designing optimal forms for terms and nomens were worked out on the basis of practical experience and theoretical analysis (terminology design projects carried out by P.V. Veselov, N.I. Kulish, E.A. Sorokina). We already mentioned some principles of convergent policy of related languages concerning borrowing (Griniewicz 2006: 14-15); a similar approach may be used in coordinating means of derivation. Already in the 1980s it was found that enormous quantities of nomens could be easily constructed according to the optimal forms and some principles of designing nomens were elaborated (Grinev 1986, 1987). There were formulated other recommendations concerning the choice of terminological forms and organizing terminological work.

Terminology advancing proper as part of national policy should consist of a number of directions and stages. One of the most important and traditional directions is ordering special vocabulary, that includes special vocabulary inventory, systematisation of special vocabulary, unification of special vocabulary and optimising special vocabulary. Another, less known, but very important direction is vocabulary construction, presupposing elaboration of banks of morphemes to be used as building material and design and construction systems of terms and nomens. Development of terminology science created possibilities of rational regulation and advancement of national languages vocabularies. However the present political situation in many newly found states rather gives ground to pessimistic prognoses concerning successful use of these possibilities.

The ideal terminology policy presupposes a number of steps, such as 
1. Choice and approval of the terminological agencies

2. Preparing the terminologists

3. Analysis of the existing situation - inventory of existing documents (standards, recommendations, thesauri), choice or preparation of an upper level classification in the form of macrothesaurus or classification; analysis of the possible lacunas and concept areas to be corrected.

4. Analysis of the terminologies that need correcting and updating - collecting terms, systematisation and defining the concepts, analysis of terminology, which is carried out with the aim of establishing the existing drawbacks and consists first of semantic analysis, with the aim to find out various deviations from the one-to-one correspondence between the lexical and terminological meanings of terms; then etymological analysis - to establish the most effective means and patterns of producing terms in the chosen subject field as well as the existing unsuitable forms and means of their improvement or substitution; functional analysis to find peculiarities of usage of terms and finally diachronic analysis to discover tendencies of development of the chosen terminology.

5. Ordering terminology, preparing new term systems

6. Introducing terminological systems - preparing standards, recommendations, thesauri and manuals

7. Expertise of the state documents, beginning with the constitution and legal acts (cf. Terminology Planning).

In this work the results of applied research should be considered, such as an optimal model of forming new terms, suggested by P.V. Veselov in the domain of imitation leather products, which may be used in other domains, or recommendations on the choice of preferable means of forming new terms on various stages of development of terminologies in European languages presented in (Grinev 1979).

Another example of successful terminological work was elaboration of terminology of carpology. In 1991, such a project was launched by the Russian Institute of Carpology. It was long felt that the abundance of incidental foreign terms in the modern Russian botanical terminology upsets its lucidity, simplicity and systemic character. This terminology has been founded on the Russian roots in the early 19 century by the Russian botanists. But then, lots of terms, either borrowed or clumsily translated were introduced by various specialists in the 19 century, which lead to the existence of various names for the same concept; in many cases there is a complete discrepancy between the lexical meaning of the Latin base and current definitions, some Latin roots have many meanings, sometimes quite different, even the opposite, which causes ambiguity in the whole system of concepts. Some suggested Russian terms were too clumsy, i.e. mnogovenechnik, obdiplostimonnyj and similar forms. A similar situation was observed in the terminology of flowers as the result of the rapid development of flower morphology and anatomy. Generally speaking, almost every author of a manual on botany (and there were more than twenty) suggested his own terms, which lead to an extremely complicated terminological situation, some concepts having up to 40 names.

The development of carpology resulted in a new classification of fruits, quite different from what was introduced by Linnaeus in the 18 century. Instead of the original four classes berry, capsule, nut and stone fruit (jagoda, korobochka, oreh, kostjanka) eight classes are singled out now. Updating the whole fruit classification required introduction of more than sixty new terms for naming newly found varieties of fruit. It was found that transliteration of 
Latin names would result in some unpronounceable forms and inconsistency with the existing Russian basic terms. Therefore, it was suggested that the formation of the Russian botanical term system on the Russian roots should continue with the aim of producing forms that would be easy to pronounce, easy to understand, easy to produce derived forms and having no negative connotations. A thorough investigation the Russian derivational resources was carried out and as the result a whole system of the basic and derived terms was proposed for types of fruit - additionally - kora (bark), jadro (nucleus), kost' (bone) and kozha (peel). With the derivatives that would make a paradigm, for example:

jagoda (berry) - jagodovnik - jagodka - jagodovinka, jagodovka, jagodovina, jagodinka, jagodinovka, jagodina;

jadro (nucleus) - jadrec-jadrovnik-jadreshek - jadrovinka-jadrovka-jadrovina - jadrinka - jadrinovka - jadrina

Some foreign terms have been changed to the newly proposed terms which are formed on the basis of the Russian roots andropetaly - lepestiki, ekzokarpij - naplodije, mezokarpijmezhplodije, hipantij-chashecwetnik, karcerula - kostec, apocarpus - raznoplodnyj.

This endeavour was not limited to the Russian language, because according to the existing rules, the whole system had to be constructed and presented for approval at the nearest Paris congress in 12 main European languages. It was approved with small changes in some languages and what is most important - the new manual based on the newly constructed terminological system clearly reflecting the respective system of concepts was published ten years ago and there are already several generations of specialists whose knowledge is based on these terms.

Thus we should recognize an advent of a new, very effective terminological product a manual based on the preliminary ordered term system. It is known that usually there is reluctance of specialists to change to new terms. In this ideal case there is no reluctance because the students did not know of the existence of a previous very intricate terminological situation and those who knew were enticed by the strict logics and transparency of the new term system. Such approach helps building systemic personal special knowledge and beliefs.

Another case was elaboration of international terminology of surgical operations in abdominal surgery by prof. N.I. Kulish. More than 200 terms constructed as a system on the basis of the widely known medical and biological term-elements were even patented by him and used in a number of methodical and teaching materials.

Presently, we evidence the emergence of a new, very broad-scoped and important science dealing with making vital decisions concerning languages which we suggest to name linguopolitology. At the present time, there are no reasons to view many political decisions concerning languages as a planned activity. However, progress in a number of adjacent fields of knowledge, such as sociolinguistics, ethnolinguistics, anthropolinguistics and terminology science creates possibilities of working out rational systemic foundations of language policy, first of all in terminology planning and management. It is still problematic, whether these possibilities would be realised; there are reasons to believe that rather not. Still, appearance of a new linguistic discipline having both highly interesting theoretical and important practical aspects should be considered as an important step in cultural progress.

\section{References}

Alpatov V.M. 2005. Language situation in regions of the present-day Russia (in Russian) Otechestvennyje zapiski. - Moscow, № 2(23). 
Ammon U. 2005. Language Politics In: Encyclopedia of Language and Linguistics, 2nd Ed. Elsevier.

Blommaert J. 2006. Language ideology In: Encyclopedia of Language and Linguistics, 2nd Ed. Elsevier.

de Cillia R. and Busch B. 2006. Language Policies: Policies on Language in Europe In: Encyclopedia of Language and Linguistics, 2nd Ed., Elsevier.

Desheriev Ju.D. 1990. Language Policy. In: Encyclopaedic dictionary "Linguistics”. Moscow, Soviet Encyclopaedia (in Russian).

Grenoble L. 2006. Endangered Languages In: Encyclopedia of Language and Linguistics, 2nd Ed. Elsevier.

Grinev S.V. 1979. Compiling a Thesaurus. Fachsprache, Wien, No.4, 154-161.

Grinev S.V. 1986. Perspectives and prerequisites of regulating nomenclature units (in Rus.). Nauchno-tehnicheskaya terminologia. Moscow, VNIIKI, No.10,1-5.

Grinev S.V. 1987. Principles of regulating technical nomenclature units (in Rus.). Nauchnotehnicheskaya terminologia. Moscow, VNIIKI, No.1,6-10.

Grinev S.V. 1993. The Perspectives of Terminology Theory: the Quest For Regularities // Selected Readings in Russian Terminology Research. Wien, 13-27.

Grinev S.V. 1994. Theoretical Foundations of Russian Terminology Work: Peculiarities and Perspectives // Applications and Implications. Current LSP Research. Vol.1. Bergen, .4956.

Grinev-Griniewicz S.V. 2008. Terminology Science: a manual for the higher education students. Moscow, Akademia (in Russian).

Griniewicz, Siergiusz. 2006. Terminology in the era of globalisation // Terminologija. No.13.. Vilnius.

Guidelines for Terminology Policies. Formulating and implementing terminology policy in language communities / prepared by Infoterm. Paris: UNESCO, 2005. ix, 39 p.; $30 \mathrm{~cm}$. (CI-2005/WS/4).

Kulisz N.I. 1984. Methodics of creating international nomenclature of surgical operations (in Rus.). - Nauchno-tehnicheskaya terminologia. Moscow, VNIIKI, No.6.

Paulston C. B. 1997. 'Language policies and language rights.' Annual Review of Anthropology 26, 73-85.

Shvejtser A.D. (1990) Sociolinguistics. In: Encyclopaedic dictionary "Linguistics". Moscow, Soviet Encyclopaedia (in Russian).

Sorokina E.A. 2007. Cognitive aspects of lexical design (Towards fundamentals of cognitive terminology science). Moscow, Publishing house MGOU.

Spolsky B., Lambert R.D. 2006. Language Planning and Policy: Models In: Encyclopedia of Language and Linguistics, 2nd Ed Elsevier.

The Oxford Companion to the English language. 1992. Oxford-New York, Oxford University Press.

Veselov P.V. 1971. Structure of terms of definitial type (On the material of terminology of plastics and soft imitation leather products) (in Russian): Dis.Cand. Philology. Moscow.

Vinogradov V.A. 1990. Language Situation. In: Encyclopaedic dictionary "Linguistics" Moscow, Soviet Encyclopaedia (in Russian). 